\title{
IMPLEMENTASI PEMBELAJARAN KOOPERATIF METODE TEAM ACCELERATED INSTRUCTION (TAI) PADA MATA PELAJARAN AKUNTANSI UNTUK MENINGKATKAN MOTIVASI DAN HASIL BELAJAR
}

\author{
Yohan Bakhtiar \\ Pascasarjana Universitas Brawijaya \\ Yohan_Bakhtiar@yahoo.co.id
}

\begin{abstract}
The purpose of this research is to know about implementation of cooperative learning using Team Accelerated Instruction (TAI) to increase motivation and student's achievement. This research is classroom action research. The subject of this research are students in Accounting subject in SMKN 2 Nganjuk. Collecting data using post test, interview, observation, questionnaire and documentation. The result show that motivation both of intrinsic and extrinsic can improve student's achievement. This research also show that implementation of cooperative learning using Team Accelerated Instruction (TAI) better than conventional method.
\end{abstract}

Keywords: Cooperative learning, Team Accelerated Instruction, motivation, student achievement

\begin{abstract}
Abstrak: Penelitian ini bertujuan untuk mengetahui implementasi pembelajaran kooperatif metode Team Accelerated Instruction (TAI) agar dapat meningkatkan motivasi dan hasil belajar. Penelitian ini merupakan jenis penelitian tindakan kelas (PTK). Subjek penelitian adalah siswa program keahlian akuntansi di SMKN 2 Nganjuk. Teknik pengumpulan data dalam penelitian ini menggunakan tes tertulis, pedoman wawancara, lembar observasi, angket motivasi siswa, dan dokumentasi. Hasil penelitian ini menunjukkan bahwa motivasi belajar baik intrinsik dan ekstrinsik dapat meningkatkan hasil belajar. Penelitian ini juga membuktikan bahwa implementasi pembelajaran kooperatif metode Team Accelerated Instruction (TAI) lebih baik daripada metode konvensional (ceramah).
\end{abstract}

Kata Kunci : Pembelajaran Kooperatif, Team Accelerated Instruction, Motivasi, Hasil Belajar

Peran penting pendidikan bagi bangsa dan negara ini sangatlah besar, sehingga perlu adanya dukungan dari segenap elemen masyarakat dan para insan akademisi untuk memajukan perkembangan pendidikan di Indonesia. Pendidikan adalah usaha sadar dan terencana untuk mewujudkan suasana belajar dan proses pembelajaran agar peserta didik secara aktif mengembangkan potensi dirinya untuk memiliki kekuatan spiritual keagamaan, pengendalian diri, kepribadian, kecerdasan, akhlak mulia, serta keterampilan yang diperlukan 
dirinya, masyarakat, bangsa dan negara (UU Sisdiknas No. 20 tahun 2003 pasal 1). Konsepsi inilah yang seharusnya menjadi suatu pemahaman bersama guna mewujudkan hakikat pendidikan nasional.

Pelaksanaan proses belajar mengajar yang ideal adalah dengan mengikuti perkembangan ilmu pengetahuan, baik itu dari buku pelajaran yang up to date hingga guru mengajar dengan berbagai model pembelajaran yang terbaru sehingga peserta didik pun antusias dan semangat untuk belajar. Akan tetapi pada kenyataannya di lapangan, masih banyak guru yang menggunakan metode konvensional yaitu ceramah sehingga membuat peserta didik pasif dalam proses pembelajaran. Guru lebih menekankan pada penghafalan konsep dari pada pemahaman terhadap materi yang diberikan. Menurut Hebert (dalam Sardiman, 2001:96) menyatakan bahwa jiwa adalah keseluruhan tanggapan yang secara mekanis dikuasai oleh hukum-hukum asosiasi. Selaras dengan pendapat tersebut jika dikaitkan dengan proses pembelajaran bahwa seharusnya peserta didik mendapatkan ilmu pengetahuan bukan hanya dari guru (teacher centered) melainkan dari proses belajar yang mereka alami sendiri sehingga pemahaman terkait materi pelajaran semakin baik dan tidak sekedar menghafalnya.

Berawal dari ini semua, maka diperlukan sebuah inovasi untuk mengatasi fenomena ini demi kemajuan pendidikan di Indonesia yaitu sebuah ide pembaharuan dalam dunia pendidikan yang meliputi pembaharuan kurikulum, peningkatan kualitas pembelajaran, dan efektifitas metode pembelajaran (Nurhadi dkk., 2004:1). Langkah-langkah konkrit demi mendukung pelaksanaan program pembaharuan ini harus menjadi titik prioritas oleh pemerintah agar prosesnya berjalan dengan lancar, tepat sasaran, efektif dan efisien. Salah satu konsep (strategi) untuk meningkatkan keaktifan peserta didik dalam proses belajar mengajar adalah dengan melibatkan langsung peserta didik dalam diskusi-diskusi maupun kelompok-kelompok belajar sehingga keberanian untuk bertanya dan berdiskusi dengan peserta didik yang lain akan muncul. Dengan demikian, peserta didik akan terpacu untuk berkompetisi dengan peserta didik yang lain untuk mendapatkan ilmu yang sebanyakbanyaknya. Namun, sebagai catatan bahwa perlu adanya sebuah perencanaan dalam pengaturan kondisi kelas sehingga kendala-kendala dalam penerapan konsep ini tidak menghambat esensi dari pembelajaran.

Berbagai metode pembelajaran telah dikembangkan untuk meningkatkan keterlibatan peserta didik dalam proses pembelajaran dengan tujuan peningkatan kualitas pendidikan. Hal ini selaras dengan langkah pembaharuan yang telah direncanakan sebelumnya guna pengembangan dunia pendidikan. Salah satu pendekatan pembelajaran 
yang berkembang adalah pendekatan kooperatif (Cooperatif Learning) dimana peserta didik dituntut untuk mandiri (aktif) dalam menguasai materi pelajaran yang diberikan daripada mendapat informasi dari ceramah guru. "Dengan pendekatan kontekstual, peserta didik dibantu menguasai kompetensi yang dipersyaratkan. Dalam kurikulum berbasis kompetensi, peserta didik akan dibawa tidak hanya masuk ke kawasan pengetahuan, tetapi juga sampai pada penerapan pengetahuan yang didapatkannya melalui pembelajaran kontekstual." (Nurhadi, dkk 2004:5).

Metode-metode pembelajaran kooperatif (Cooperatif Learning) memang tepat jika diterapkan dalam kelas yang heterogen karena dapat menimbulkan suasana belajar yang kondusif yaitu dengan saling berinteraksinya antar siswa dalam proses belajar mengajar. Salah satu model pembelajaran kooperatif yang tepat untuk diterapkan pada kondisi kelas yang heterogen adalah metode Team Accelerated Instruction (TAI). Menurut Slavin (2008:189) Team Accelerated Instruction diprakarsai sebagai usaha merancang sebuah bentuk pengajaran individual yang bisa menyelesaikan masalah-masalah yang membuat metode pengajaran individual menjadi tidak efektif". Dengan membuat para siswa bekerja dalam tim-tim pembelajaran kooperatif dan mengemban tanggung jawab mengelola dan memeriksa secara rutin, saling membantu satu sama lain dalam menghadapi masalah, dan saling memberi dorongan untuk maju, maka guru dapat membebaskan diri mereka dari memberikan pengajaran langsung kepada sekelompok kecil siswa yang homogen, dan berasal dari kelompok siswa yang heterogen. Jadi penerapan metode Team Accelerated Instruction (TAI) dapat mengatasi permasalahan - permasalahan yang terjadi selama proses pembelajaran di kelas dengan efektif sehingga peserta didik dapat memahami materi pelajaran dengan baik dan hal yang terpenting adalah kegiatan belajar mengajar menjadi lebih menyenangkan.

\section{METODE}

Penelitian ini menggunakan subyek siswa kelas X KU 1 program keahlian akuntansi di SMKN 2 Nganjuk karena berdasarkan hasil observasi pendahuluan sebelum dilakukan penelitian ini disimpulkan bahwa di sekolah ini proses belajar mengajar masih menggunakan metode konvensional (ceramah) dalam kegiatan belajar mengajarnya sehingga para siswa menjadi bosan dan hal ini tentu saja berdampak pada hasil belajar mereka. Peneliti menggunakan paradigma interpretif sebagai kerangka berfikirnya. Paradigma ini menekankan pada peranan bahasa, interpretasi dan pemahaman terhadap apa yang menjadi objek penelitian (Chua, 1969). Menurut Burrell dan Morgan (1979), paradigma ini menggunakan cara pandang nominalis yang didasari oleh paham nominalism. Paham ini melihat realitas 
sosial sebagai sesuatu yang berupa label, nama atau konsep yang digunakan untuk membangun realitas.

Pendekatan penelitian yang dipakai dalam studi ini adalah pendekatan kualitatif dan kuantitatif deskriptif. Menurut Moleong (2007:6) bahwa penelitian kualitatif adalah penelitian yang bermaksud untuk memahami fenomena tentang apa yang dialami oleh subjek peneliti misalnya perilaku, persepsi, motivasi, tindakan, dan lain-lain, secara holistik, dan dengan cara deskripsi dalam bentuk kata-kata dan bahasa, pada suatu konteks khusus yang alamiah dan dengan memanfaatkan berbagai metode alamiah. Jenis penelitian ini adalah Penelitian Tindakan Kelas (Classroom Action Research). Menurut Hopkins (dalam Danawati, 2008:62) penelitian tindakan kelas adalah penelitian yang mengkombinasikan prosedur penelitian dengan tindakan substantif, suatu tindakan yang dilakukan dalam disiplin inkuiri, atau suatu usaha seseorang untuk memahami apa yang sedang terjadi, sambil terlibat dalam sebuah proses perbaikan dan perubahan.

Peneliti berencana untuk menerapkan dua siklus dalam penelitian ini. PTK merupakan penelitian proses pembelajaran di kelas yang berdaur dan terdiri dari 4 (empat) tahap, yaitu; 1) perencanaan/planning, 2) pelaksanaan tindakan/action, 3) pengamatan/observation, 4) refleksi/reflection (dalam Wulansari, 2008:38). Teknik pengumpulan data dalam penelitian ini menggunakan observasi, wawancara (interview), kuesioner (angket), test, catatan lapangan, dan dokumentasi.

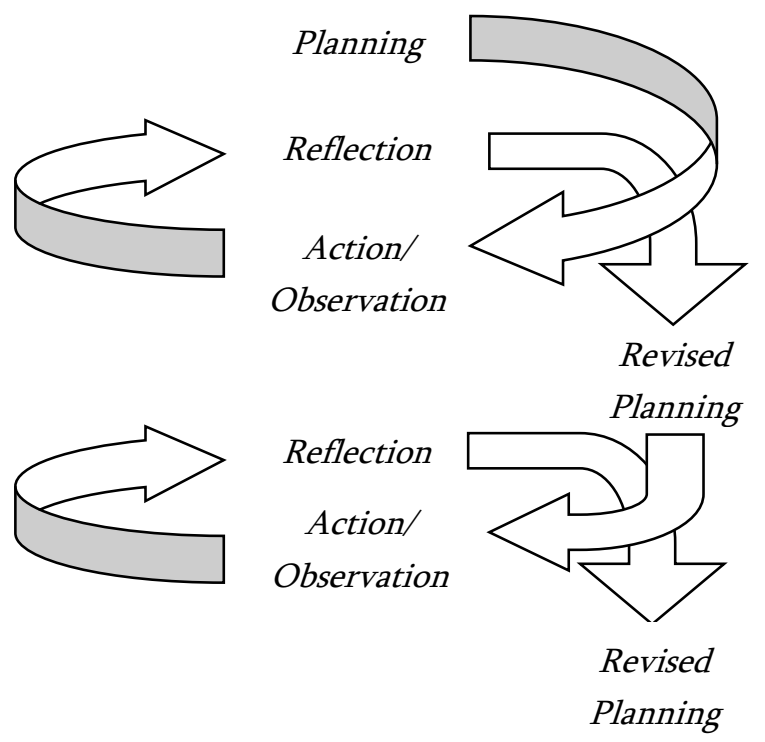

Gambar 1. Spiral Penelitian Tindakan Kelas (PTK) Siklus I \& II

Untuk mencapai tujuan penelitian, maka diperlukan data-data yang konkrit terkait hasil belajar siswa baik itu sebelum penelitian maupun setelah penelitian. Maka dari itu, 
peneliti menggunakan pre-test dan post-test untuk mengetahui perkembangan hasil belajar siswa. Materi yang disajikan dalam soal sesuai dengan materi yang telah diajarkan sebelumnya yaitu memproses entri jurnal umum dan khusus pada perusahaan dagang dan jasa. Total keseluruhan siswa yang menjadi subyek penelitian adalah 36 orang dan dibagi menjadi 6 kelompok. Pembagian kelompok secara heterogen ini berdasarkan hasil pre-test yang telah dilaksanakan sebelumnya. Jadi siswa yang masuk dalam kategori pintar, tidak akan dimasukkan kedalam kelompok yang sama-sama pintar, intinya dalam satu kelompok heterogen itu terdapat siswa yang pintar, menengah dan kurang pengetahuannya. Peneliti juga menentukan ketua kelompok untuk mempermudah penyampaian informasi baik di wilayah pemberian tugas maupun metode pembelajaran yang akan diberikan.

\section{HASIL DAN PEMBAHASAN}

Pada awalnya, siswa-siswa terlihat kebingungan dalam implementasi metode Team Accelerated Instruction (TAI) karena memang metode ini belum pernah dilakukan sebelumnya sehingga wajar jika mereka belum bisa merasakan manfaat dari metode ini dalam proses belajar mengajar. Namun, seiring berjalannya waktu penelitian, mereka sudah terbiasa dan enjoy dengan situasi yang baru dan menyenangkan ini.

Peneliti menggunakan analisis statistik deskriptif dalam proses penyajian data hasil penelitian. Dalam pelaksanaan tindakan siklus I, secara umum masing-masing kelompok telah melakukan diskusi yang interaktif yaitu saling bertukar pendapat antar sesama anggota kelompok. Peneliti juga memberikan pre-test dan post-test terkait materi yang telah diberikan untuk mengukur pemahaman siswa, sebelum dan sesudah perlakuan metode Team Accelerated Instruction (TAI). Berikut ini hasil pre-test siswa sebelum implementasi metode Team Accelerated Instruction (TAI).

Tabel 1 Hasil pre-test

\begin{tabular}{|c|l|c|c|c|}
\hline No. & \multicolumn{1}{|c|}{ Nama Siswa } & L/P & Nilai & Keterangan \\
\hline 1. & Abdul Jalil & $\mathrm{L}$ & 90 & TUNTAS \\
\hline 2. & Agustinah & $\mathrm{P}$ & 81 & TUNTAS \\
\hline 3. & Amin Supiati & $\mathrm{P}$ & - & - \\
\hline 4. & Anita Sulistiana & $\mathrm{P}$ & 65 & BELUM TUNTAS \\
\hline 5. & Apriani Catur Pamungkas & $\mathrm{P}$ & 51 & BELUM TUNTAS \\
\hline 6. & Arsita Suryanira & $\mathrm{P}$ & 80 & TUNTAS \\
\hline 7. & Asri Winarsih & $\mathrm{P}$ & 75 & TUNTAS \\
\hline 8. & Atika Dian Pramayanti & $\mathrm{P}$ & 80 & TUNTAS \\
\hline 9. & Atikco Sary & $\mathrm{P}$ & 75 & TUNTAS \\
\hline 10. & Ayu Dwi Ningsih & $\mathrm{P}$ & 50 & BELUM TUNTAS \\
\hline 11. & Ayu Priska Ariyanti & $\mathrm{P}$ & 65 & BELUM TUNTAS \\
\hline 12. & Ayu Sulistyo Gracy Ningrum & $\mathrm{P}$ & 75 & TUNTAS \\
\hline
\end{tabular}




\begin{tabular}{|c|l|c|c|c|}
\hline 13. & Ayu Suwarni & $\mathrm{P}$ & 50 & BELUM TUNTAS \\
\hline 14. & Betharia Laily & $\mathrm{P}$ & 71 & TUNTAS \\
\hline 15. & Binti Latifah Jaiyida & $\mathrm{P}$ & 85 & TUNTAS \\
\hline 16. & Brilyani Nur Indah Lukita S. & $\mathrm{P}$ & 60 & BELUM TUNTAS \\
\hline 17. & Della Retno Ayu Fitri & $\mathrm{P}$ & 80 & TUNTAS \\
\hline 18. & Desi Miftakul Janah & $\mathrm{P}$ & 85 & TUNTAS \\
\hline 19. & Desy Tri Wahyuni & $\mathrm{P}$ & 75 & TUNTAS \\
\hline 20. & Dewi Fatikatur Rohmah & $\mathrm{P}$ & 90 & TUNTAS \\
\hline 21. & Dewi Sulasih & $\mathrm{P}$ & 65 & BELUM TUNTAS \\
\hline 22. & Dian Ayu Apriliani & $\mathrm{P}$ & 60 & BELUM TUNTAS \\
\hline 23. & Dian Rizki Rahmawati & $\mathrm{P}$ & 65 & BELUM TUNTAS \\
\hline 24. & Diana Ayu Savitri & $\mathrm{P}$ & 55 & BELUM TUNTAS \\
\hline 25. & Dina Rochma Hidayah & $\mathrm{P}$ & 75 & TUNTAS \\
\hline 26. & Duwi Lestari & $\mathrm{P}$ & 65 & BELUM TUNTAS \\
\hline 27. & Dwi Ekasari & $\mathrm{P}$ & 63 & BELUM TUNTAS \\
\hline 28. & Dwi Oktavia Ningtias & $\mathrm{P}$ & 75 & TUNTAS \\
\hline 29. & Dyah Gunarti & $\mathrm{P}$ & 80 & TUNTAS \\
\hline 30. & Eka Ratna Agustina Saputri & $\mathrm{P}$ & 71 & TUNTAS \\
\hline 31. & Eka Yusinta & $\mathrm{P}$ & 70 & TUNTAS \\
\hline 32. & Eko Prasetyo & $\mathrm{L}$ & - & - \\
\hline 33. & Ela Yusiana & $\mathrm{P}$ & 51 & BELUM TUNTAS \\
\hline 34. & Endah Setyoningrum & $\mathrm{P}$ & 65 & BELUM TUNTAS \\
\hline 35. & Erni Megawati & $\mathrm{P}$ & 70 & TUNTAS \\
\hline 36. & Evin Suherlin & $\mathrm{P}$ & 61 & BELUM TUNTAS \\
\hline Jumlah & & $\mathbf{2 3 7 4}$ & \\
\hline Rata-Rata & & $\mathbf{6 9 , 8 2}$ & \\
\hline$\sum$ Siswa yang tuntas & & $\mathbf{1 9} \mathbf{( 5 5 , 8 8 \% )}$ & $(\mathbf{4 4 , 1 2 \% )}$ & \\
\hline$\sum$ Siswa yang belum tuntas & & \\
\hline $\mathbf{S}$ & & \\
\hline
\end{tabular}

Sumber : Data olahan peneliti

Seperti yang tertera pada tabel, bahwa peserta didik yang mengikuti pre-test adalah 34 dari 36 jumlah keseluruhan peserta didik. Hal ini dikarenakan ada dua peserta didik yang tidak masuk karena sakit. Peserta didik yang tuntas sebanyak 19 orang dengan persentase $55,88 \%$ sedangkan yang belum tuntas sebanyak 15 orang dengan persentase $44,12 \%$.

Nilai post-test ini dihasilkan dari nilai tes peserta didik setelah mendapat perlakuan tindakan pembelajaran kooperatif metode Team Accelerated Instruction (TAI). Hasil post-test ini disajikan disajikan dalam tabel berikut ini.

Tabel 2 Hasil post-test siklus I

\begin{tabular}{|c|l|c|c|c|}
\hline No. & \multicolumn{1}{|c|}{ Nama Siswa } & L/P & Nilai & Keterangan \\
\hline 1. & Abdul Jalil & $\mathrm{L}$ & 85 & TUNTAS \\
\hline 2. & Agustinah & $\mathrm{P}$ & 90 & TUNTAS \\
\hline 3. & Amin Supiati & $\mathrm{P}$ & 70 & TUNTAS \\
\hline 4. & Anita Sulistiana & $\mathrm{P}$ & 75 & TUNTAS \\
\hline 5. & Apriani Catur Pamungkas & $\mathrm{P}$ & 50 & BELUM TUNTAS \\
\hline 6. & Arsita Suryanira & $\mathrm{P}$ & 85 & TUNTAS \\
\hline 7. & Asri Winarsih & $\mathrm{P}$ & 70 & TUNTAS \\
\hline 8. & Atika Dian Pramayanti & $\mathrm{P}$ & 80 & TUNTAS \\
\hline 9. & Atikco Sary & $\mathrm{P}$ & 55 & BELUM TUNTAS \\
\hline
\end{tabular}




\begin{tabular}{|c|c|c|c|c|}
\hline 10. & Ayu Dwi Ningsih & $\mathrm{P}$ & 90 & TUNTAS \\
\hline 11. & Ayu Priska Ariyanti & $\mathrm{P}$ & 80 & TUNTAS \\
\hline 12. & Ayu Sulistyo Gracy Ningrum & $\mathrm{P}$ & 85 & TUNTAS \\
\hline 13. & Ayu Suwarni & $\mathrm{P}$ & 60 & BELUM TUNTAS \\
\hline 14. & Betharia Laily & $\mathrm{P}$ & 70 & TUNTAS \\
\hline 15. & Binti Latifah Jaiyida & $\mathrm{P}$ & 85 & TUNTAS \\
\hline 16. & Brilyani Nur Indah Lukita S. & $\mathrm{P}$ & 75 & TUNTAS \\
\hline 17. & Della Retno Ayu Fitri & $\mathrm{P}$ & 80 & TUNTAS \\
\hline 18. & Desi Miftakul Janah & $\mathrm{P}$ & 95 & TUNTAS \\
\hline 19. & Desy Tri Wahyuni & $\mathrm{P}$ & 85 & TUNTAS \\
\hline 20. & Dewi Fatikatur Rohmah & $\mathrm{P}$ & 65 & BELUM TUNTAS \\
\hline 21. & Dewi Sulasih & $\mathrm{P}$ & 75 & TUNTAS \\
\hline 22. & Dian Ayu Apriliani & $\mathrm{P}$ & 80 & TUNTAS \\
\hline 23. & Dian Rizki Rahmawati & $\mathrm{P}$ & 45 & BELUM TUNTAS \\
\hline 24. & Diana Ayu Savitri & $\mathrm{P}$ & 55 & BELUM TUNTAS \\
\hline 25. & Dina Rochma Hidayah & $\mathrm{P}$ & 85 & TUNTAS \\
\hline 26. & Duwi Lestari & $\mathrm{P}$ & 65 & BELUM TUNTAS \\
\hline 27. & Dwi Ekasari & $\mathrm{P}$ & 60 & BELUM TUNTAS \\
\hline 28. & Dwi Oktavia Ningtias & $\mathrm{P}$ & 80 & TUNTAS \\
\hline 29. & Dyah Gunarti & $\mathrm{P}$ & 80 & TUNTAS \\
\hline 30. & Eka Ratna Agustina Saputri & $\mathrm{P}$ & 75 & TUNTAS \\
\hline 31. & Eka Yusinta & $\mathrm{P}$ & 85 & TUNTAS \\
\hline 32. & Eko Prasetyo & $\mathrm{L}$ & 75 & TUNTAS \\
\hline 33. & Ela Yusiana & $\mathrm{P}$ & 45 & BELUM TUNTAS \\
\hline 34. & Endah Setyoningrum & $\mathrm{P}$ & 90 & TUNTAS \\
\hline 35. & Erni Megawati & $\mathrm{P}$ & 75 & TUNTAS \\
\hline 36. & Evin Suherlin & $\mathrm{P}$ & 80 & TUNTAS \\
\hline \multicolumn{3}{|c|}{ Jumlah } & 2680 & \\
\hline \multicolumn{3}{|c|}{ Rata-Rata } & 74,44 & \\
\hline \multicolumn{3}{|c|}{$\sum$ Siswa yang tuntas } & $27(75 \%)$ & \\
\hline \multicolumn{3}{|c|}{$\sum$ Siswa yang belum tuntas } & $9(25 \%)$ & \\
\hline
\end{tabular}

Sumber : Data olahan peneliti

Untuk nilai post-test ini didapatkan dari keseluruhan jumlah peserta didik karena semuanya masuk pada saat diadakan post-test. Dari tabel diatas dapat dilihat bahwa peserta didik yang tuntas sebanyak 27 orang dengan persentase $75 \%$ sedangkan yang belum tuntas sebanyak 9 orang dengan persentase $25 \%$.

Penyusunan angket motivasi belajar peserta didik berupa pernyataan-pernyataan yang disusun berdasarkan skala Likert yang digunakan untuk mengukur sikap, pendapat, persepsi responden terhadap suatu objek. Dengan skala Likert, maka variabel yang akan diukur dijabarkan menjadi indikator variabel. Kemudian indikator tersebut dijadikan sebagai titik tolak untuk menyusun item-item instrumen yang dapat berupa pernyataan atau pertanyaan (Sugiyono, 2008:93). Total keseluruhan dari butir soal motivasi adalah 28 dengan 14 butir soal motivasi intrinsik dan 14 butir motivasi ekstrinsik. 
Berikut adalah tabel ringkasan hasil angket motivasi belajar yang telah diisi oleh seluruh siswa yang menjadi subyek dalam penelitian ini.

Tabel 3 Hasil angket motivasi belajar

\begin{tabular}{|l|c|c|}
\hline \multicolumn{1}{|c|}{ Jenis Motivasi } & Skor Rata-Rata & Taraf Keberhasilan \\
\hline Intrinsik & 3,17 & Baik \\
\hline Ekstrinsik & 3,00 & Baik \\
\hline
\end{tabular}

Sumber : Data olahan peneliti

Berdasarkan tabel diatas, dapat dilihat bahwa pada motivasi intrinsik memiliki skor rata-rata 3,17 dengan taraf keberhasilan baik. Sedangkan motivasi ekstrinsik memiliki skor rata-rata 3,00 dengan taraf keberhasilan sama yaitu baik. Disini terlihat bahwa secara umum peserta didik lebih termotivasi secara intrinsik yaitu dari dalam dirinya sendiri untuk belajar.

Berdasarkan catatan lapangan yang telah dirumuskan oleh kedua observer selama berlangsungnya pembelajaran kooperatif metode Team Accelerated Instruction (TAI) maka dapat diperoleh beberapa informasi yang terkait antara lain sebagai berikut :

a) Pada permulaan penerapan pembelajaran kooperatif dengan metode Team Accelerated Instruction (TAI), peserta didik banyak yang gaduh karena masih bingung dengan metode ini.

b) Pembagian waktu yang telah direncanakan dalam rencana pelaksanaan pembelajaran kurang berjalan dengan baik.

c) Hanya ada beberapa peserta didik yang terlibat aktif dalam pembelajaran sehingga guru mencoba untuk memotivasi agar ikut aktif.

d) Kadangkala guru terlalu cepat dalam menerangkan materi pelajaran.

e) Ada beberapa peserta didik dalam satu kelompok yang ramai sendiri sehingga mengganggu teman-temannya di kelompok yang lain

Refleksi digunakan untuk mengevaluasi apakah tindakan pembelajaran kooperatif metode Team Accelerated Instruction (TAI) sudah diterapkan dengan baik sesuai dengan tujuan yang diharapkan pada siklus I ini. Tahap refleksi ini dilakukan pada setiap akhir pembelajaran sehingga hasil dari refleksi ini dapat dijadikan acuan untuk meningkatkan kualitas pembelajaran pada siklus selanjutnya jika memang dirasakan hasilnya kurang dari target yang telah direncanakan pada awal pembelajaran.

Berdasarkan paparan data yang diperoleh dari hasil observasi selama proses penelitian, secara umum memang penerapan pembelajaran kooperatif metode Team Accelerated Instruction (TAI) dapat meningkatkan hasil belajar dan juga motivasi belajar peserta didik dalam mata pelajaran akuntansi. Namun peneliti merasa ada beberapa hal yang 
kurang optimal baik berupa tindakan maupun hasil dalam penelitian ini sehingga peneliti menyimpulkan untuk melanjutkan penelitian pada siklus selanjutnya (siklus II).

Pada hakikatnya, kegiatan yang dilakukan pada siklus II sama halnya dengan siklus I meliputi 4 tahap, yaitu perencanaan tindakan, pelaksanaan tindakan, observasi tindakan dan refleksi tindakan. Perencanaan yang dilakukan pada siklus II ini mengacu pada hasil refleksi pada siklus sebelumnya. Hal-hal yang dilakukan oleh peneliti pun tidak jauh berbeda dengan perencanaan pada siklus sebelumnya akan tetapi tidak mendetail seperti pada siklus sebelumnya, karena tujuan utama pada siklus II ini adalah memperbaiki jalannya pembelajaran yang dirasa masih kurang pada siklus sebelumnya.

Pelaksanaan pembelajaran pada siklus II ini lebih ditekankan pada hasil refleksi siklus sebelumnya dengan harapan pembelajaran pada siklus kedua ini bisa mencapai hasil seperti yang diharapkan. Pada akhir pembelajaran, peneliti memberikan post-test II sebagai evaluasi atas kemampuan siswa setelah diberi perlakuan berupa pembelajaran Team Accelerated Instruction (TAI).

Tabel 4. Hasil post-test silkus II

\begin{tabular}{|c|c|c|c|c|}
\hline No. & Nama Siswa & $\mathbf{L} / \mathbf{P}$ & Nilai & Keterangan \\
\hline 1. & Abdul Jalil & $\mathrm{L}$ & 94 & TUNTAS \\
\hline 2. & Agustinah & $\mathrm{P}$ & 90 & TUNTAS \\
\hline 3. & Amin Supiati & $\mathrm{P}$ & 73 & TUNTAS \\
\hline 4. & Anita Sulistiana & $\mathrm{P}$ & 85 & TUNTAS \\
\hline 5. & Apriani Catur Pamungkas & $\mathrm{P}$ & 60 & BELUM TUNTAS \\
\hline 6. & Arsita Suryanira & $\mathrm{P}$ & 82 & TUNTAS \\
\hline 7. & Asri Winarsih & $\mathrm{P}$ & 88 & TUNTAS \\
\hline 8. & Atika Dian Pramayanti & $\mathrm{P}$ & 85 & TUNTAS \\
\hline 9. & Atikco Sary & $\mathrm{P}$ & 93 & TUNTAS \\
\hline 10. & Ayu Dwi Ningsih & $\mathrm{P}$ & 80 & TUNTAS \\
\hline 11. & Ayu Priska Ariyanti & $\mathrm{P}$ & 80 & TUNTAS \\
\hline 12. & Ayu Sulistyo Gracy Ningrum & $\mathrm{P}$ & 70 & TUNTAS \\
\hline 13. & Ayu Suwarni & $\mathrm{P}$ & - & - \\
\hline 14. & Betharia Laily & $\mathrm{P}$ & 88 & TUNTAS \\
\hline 15. & Binti Latifah Jaiyida & $\mathrm{P}$ & 83 & TUNTAS \\
\hline 16. & Brilyani Nur Indah Lukita S. & $\mathrm{P}$ & - & - \\
\hline 17. & Della Retno Ayu Fitri & $\mathrm{P}$ & 92 & TUNTAS \\
\hline 18. & Desi Miftakul Janah & $\mathrm{P}$ & 90 & TUNTAS \\
\hline 19. & Desy Tri Wahyuni & $\mathrm{P}$ & 80 & TUNTAS \\
\hline 20. & Dewi Fatikatur Rohmah & $\mathrm{P}$ & 86 & TUNTAS \\
\hline 21. & Dewi Sulasih & $\mathrm{P}$ & 85 & TUNTAS \\
\hline 22. & Dian Ayu Apriliani & $\mathrm{P}$ & 96 & TUNTAS \\
\hline 23. & Dian Rizki Rahmawati & $\mathrm{P}$ & 83 & TUNTAS \\
\hline 24. & Diana Ayu Savitri & $\mathrm{P}$ & 85 & TUNTAS \\
\hline 25. & Dina Rochma Hidayah & $\mathrm{P}$ & 84 & TUNTAS \\
\hline 26. & Duwi Lestari & $\mathrm{P}$ & 90 & TUNTAS \\
\hline 27. & Dwi Ekasari & $\mathrm{P}$ & 55 & BELUM TUNTAS \\
\hline
\end{tabular}




\begin{tabular}{|c|l|c|c|c|}
\hline 28. & Dwi Oktavia Ningtias & $\mathrm{P}$ & 95 & TUNTAS \\
\hline 29. & Dyah Gunarti & $\mathrm{P}$ & 93 & TUNTAS \\
\hline 30. & Eka Ratna Agustina Saputri & $\mathrm{P}$ & 88 & TUNTAS \\
\hline 31. & Eka Yusinta & $\mathrm{P}$ & 75 & TUNTAS \\
\hline 32. & Eko Prasetyo & $\mathrm{L}$ & 50 & BELUM TUNTAS \\
\hline 33. & Ela Yusiana & $\mathrm{P}$ & 60 & BELUM TUNTAS \\
\hline 34. & Endah Setyoningrum & $\mathrm{P}$ & 78 & TUNTAS \\
\hline 35. & Erni Megawati & $\mathrm{P}$ & 93 & TUNTAS \\
\hline 36. & Evin Suherlin & $\mathrm{P}$ & 86 & TUNTAS \\
\hline & Jumlah & & $\mathbf{2 7 9 5}$ & \\
\hline & Rata-Rata & & $\mathbf{7 7 , 6 3}$ & \\
\hline & $\sum$ Siswa yang tuntas & & $\mathbf{3 4} \mathbf{( 8 8 , 2 4 \% )}$ & \\
\hline & $\sum$ Siswa yang belum tuntas & $\mathbf{4 ( 1 1 , 7 6 \% )}$ & \\
\hline
\end{tabular}

Sumber : Data olahan peneliti

Berdasarkan tabel diatas dapat diketahui bahwa 34 dari 36 peserta didik di kelas $\mathrm{X}$ KU 1 terdapat 30 peserta didik atau 88,24\% dinyatakan telah tuntas belajar, sementara 4 peserta didik atau 11,76\% belum tuntas belajar. Berdasarkan persentase keberhasilan belajar, pada siklus II ini secara klasikal kelas X KU 1 telah tuntas belajar.

Dalam mengukur tingkat motivasi peserta didik, peneliti menggunakan angket sebagai media pengukuran. Sama halnya dengan siklus I, total keseluruhan dari butir soal motivasi adalah 28 dengan rincian 14 butir soal motivasi intrinsik dan 14 butir motivasi ekstrinsik. Berikut adalah tabel ringkasan hasil dari angket motivasi belajar.

Tabel 5. Hasil angket motivasi belajar

\begin{tabular}{|l|c|c|}
\hline \multicolumn{1}{|c|}{ Jenis Motivasi } & Skor Rata-Rata & Taraf Keberhasilan \\
\hline Intrinsik & 3,22 & Baik \\
\hline Ekstrinsik & 3,10 & Baik \\
\hline
\end{tabular}

Sumber : Data olahan peneliti

Berdasarkan tabel diatas, dapat dilihat bahwa pada motivasi intrinsik memiliki skor rata-rata 3,22 dengan taraf keberhasilan baik. Sedangkan motivasi ekstrinsik memiliki skor rata-rata 3,10 dengan taraf keberhasilan sama yaitu baik. Jika dibandingkan dengan siklus I dapat terlihat bahwa adanya peningkatan motivasi belajar peserta didik baik untuk motivasi intrinsik maupun ekstrinsik.

Secara garis besar, pembelajaran yang terjadi selama siklus II ini telah menghasilkan banyak peningkatan baik itu di wilayah kinerja kelompok maupun individu peserta didik. Peneliti pun telah melaksanakan rencana pelaksanaan pembelajaran dengan baik sesuai dengan alokasi waktu yang telah ditentukan. Keaktifan peserta didik pada saat diskusi kelompok maupun diskusi kelas mengalami peningkatan keberhasilan tindakan yang cukup signifikan yaitu sebesar 9,44\% (dari 81,11\% - 90,55\%). Hal ini menunjukkan bahwa peserta 
didik telah nyaman dan terbiasa menggunakan pembelajaran kooperatif metode Team Accelerated Instruction (TAI).

Tabel 6. Perbandingan Aktivitas siswa pada Pembelajaran Team Accelerated Instruction (TAI)

\begin{tabular}{|l|c|c|}
\hline \multicolumn{1}{|c|}{ Keberhasilan Tindakan } & Rata-Rata Persentase Keberhasilan & Selisih \\
\hline Siklus I & $81,11 \%$ & - \\
\hline Siklus II & $90,55 \%$ & $9,44 \%$ \\
\hline
\end{tabular}

Sumber : Data olahan peneliti

Terkait dengan motivasi belajar peserta didik, pada siklus II ini juga sudah mengalami peningkatan. Untuk motivasi intrinsik, terjadi peningkatan sebesar 0,05 (dari 3,17-3,22). Sedangkan untuk motivasi ekstrinsik terjadi peningkatan sebesar 0,10 (dari 3,003,10). Memang terlihat bahwa peningkatan motivasi belajar kurang signifikan akan tetapi disini dapat disimpulkan bahwa penerapan pembelajaran kooperatif metode Team Accelerated Instruction (TAI) dapat meningkatkan motivasi belajar peserta didik jika dibandingkan dengan metode ceramah yang diterapkan sebelumnya.

Tabel 7. Tingkat keberhasilan tindakan pada motivasi belajar siswa

\begin{tabular}{|l|c|c|c|c|}
\hline \multirow{2}{*}{ Jenis Motivasi } & \multicolumn{2}{|c|}{ Taraf Keberhasilan } & \multirow{2}{*}{ Peningkatan } & \multirow{2}{*}{ Persentase } \\
\cline { 2 - 3 } & Siklus I & Siklus II & & \\
\hline Motivasi Intrinsik & 3,17 & 3,22 & 0,05 & $1,5 \%$ \\
\hline Motivasi Ekstrinsik & 3,00 & 3,10 & 0,10 & $3,33 \%$ \\
\hline
\end{tabular}

Sumber : Data olahan peneliti

Ketuntasan belajar siswa secara klasikal dihitung berdasarkan Standar Ketuntasan Minimum yang diterapkan di SMKN 2 Nganjuk yaitu peserta didik mencapai nilai 70 atau lebih. Selain itu dapat dihitung dengan menggunakan rumus sebagai berikut :

Ketuntasan Belajar $=$ Jumlah siswa yang memperoleh skor $>70$

$$
\text { Jumlah keseluruhan siswa }
$$

Berdasarkan rumus diatas maka dapat dihitung tingkat ketuntasan belajar siswa kelas $\mathrm{X}$ KU 1 SMKN 2 Nganjuk pada pembelajaran kooperatif metode Team Accelerated Instruction (TAI) baik pada siklus I maupun II, dengan hasil seperti yang nampak pada tabel berikut ini :

Tabel 8. Peningkatan Hasil Belajar Siswa

\begin{tabular}{|l|c|c|c|}
\hline \multirow{2}{*}{ Keterangan } & \multicolumn{2}{|c|}{ Prosentase Ketuntasan } & \multirow{2}{*}{ Selisih } \\
\cline { 2 - 3 } & Siklus I & Siklus II & \\
\hline Tuntas & $75 \%$ & $88,24 \%$ & $13,24 \%$ \\
\hline Belum Tuntas & $25 \%$ & $11,76 \%$ & $-13,24 \%$ \\
\hline
\end{tabular}

Sumber : Data olahan peneliti

Berdasarkan tabel diatas dapat diketahui bahwa tingkat ketuntasan belajar siswa pada pembelajaran kooperatif metode Team Accelerated Instruction (TAI) mengalami 
peningkatan sebesar $13,24 \%$ dari siklus I sebesar $75 \%$ menjadi 88,24\% pada siklus II Hal ini sesuai dengan yang pernyataan Slavin bahwa metode-metode pembelajaran kooperatif (Cooperatif Learning) memang tepat jika diterapkan dalam kelas yang heterogen karena dapat menimbulkan suasana belajar yang kondusif yaitu dengan saling berinteraksinya antar siswa dalam proses belajar mengajar dan salah satu model pembelajaran kooperatif yang tepat untuk diterapkan pada kondisi kelas yang heterogen adalah metode Team Accelerated Instruction (TAI).

\section{SIMPULAN}

Berdasarkan hasil penelitian dan pembahasan dapat disimpulkan bahwa pembelajaran kooperatif metode Team Accelerated Instruction (TAI) terbukti mampu meningkatkan motivasi belajar peserta didik dari siklus ke siklus. Walaupun peningkatannya kurang signifikan, akan tetapi disini tetap terjadi peningkatan yang berarti bahwa peserta didik mengalami peningkatan motivasi belajar secara keseluruhan. Hal ini patut untuk ditindak lanjuti oleh pihak sekolah agar dilakukan secara berkelanjutan agar hasil belajar peserta didik semakin meningkat dari waktu ke waktu.

Dengan demikian, peneliti mengambil kesimpulan bahwa penerapan pembelajaran kooperatif metode Team Accelerated Instruction (TAI) dapat meningkatkan motivasi dan hasil belajar peserta didik kelas X KU 1 di SMKN 2 Nganjuk.

\section{DAFTAR RUJUKAN}

Burrell, Gibson and Gareth Morgan. 1979. Sociological Paradigms and Organisational Analysis: Elements of the Sociology of Corporate Life. London: Heinemann.

Chua, Wai Fong. 1986. Radical developments in accounting thought. The Accounting Review LXI (4).

Danawati, M. G. 2008. Implementasi Pembelajaran Kontekstual Model Role Playing Guna Meningkatkan Hasil Belajar Siswa Pada Mata Pelajaran Merencanakan dan Melakukan Pertemuan (Studi Pada Siswa Program Keahlian Administrasi Perkantoran Kelas 2 APk 2 di SMK Muhammadiyah 3 Singosari). Malang: Skripsi tidak diterbitkan.

Departemen Pendidikan Nasional RI. 2003. Undang-Undang RI No. 20 Tahun 2003 tentang SISDIKNAS. Jakarta: Biro Hukum \& Organisasi Sekretariat Jendral Depdiknas.

Moleong, L. J. 2007. Metode Penelitian Kualitatif. Bandung: PT Remaja Rosdakarya.

Nurhadi, dkk. 2004. Pembelajaran Kontekstual dan Penerapannya dalam Kurikulum Berbasis Kompetensi. Malang: UM Press.

Sardiman. 2001. Interaksi dan motivasi belajar mengajar. Jakarta : PT. Raja Grafindo Persada. 
Slavin, R. E. 2008. Cooperative Learning Teori, Riset dan Praktik. Bandung: Penerbit Nusa Media.

Sugiyono. 2008. Metode Penelitian Kuantitatif Kualitatif Dan $R \& D$. Bandung. Penerbit Alfabeta.

Wulansari, P. 2008. Penerapan Pembelajaran Kooperatif Model Think-Pair-Share (TPS) dalam Pembelajaran Mata Diklat Akuntansi Siswa Kelas 1 Ak 1 di SMK Negeri 2 Kediri. Malang: Skripsi tidak diterbitkan. 